\title{
Motivação e Autorregulação da Motivação no Contexto Educativo*
}

\author{
Motivation and Self-regulation of Motivation in the Educational Context \\ Motivación y Autorregulación de la Motivación en el Contexto Educativo
}

\author{
José Aloyseo Bzuneck \\ Universidade Estadual de Londrina. E-mail: bzuneck@sercomtel.com.br \\ Evely Boruchovitch \\ Universidade Estadual de Campinas. E-mail: evely@unicamp.br \\ *A segunda autora agradece o apoio financeiro do CNPq.
}

\section{Resumo}

A motivação é um construto-chave na Psicologia Escolar e Educacional. Assim, neste artigo, serão apresentadas, na primeira parte, linhas de ação, seletivamente baseadas em teorias motivacionais que focalizam as razões para o engajamento, tendo como fio condutor a busca de resposta a três questões básicas: O que motiva os alunos a aprender? Quem os motiva? E como? Já a segunda parte, com base nos mesmos referenciais teóricos, será devotada à reflexão sobre as seguintes questões: Como se automotivar? Que estratégias existem para ajudar os indivíduos a regularem a sua motivação no contexto educativo? Espera-se prover o leitor com informações úteis tanto para motivar alguém a aprender quanto para manter a sua própria motivação num estado ótimo e favorecedor da aprendizagem de qualidade. Tem-se a expectativa também de que esse tema seja mais amplamente difundido na formação de psicólogos.

Palavras-chave: aprendizagem, autorregulação, motivação, psicologia educacional.

\section{Abstract}

Motivation is a key-construct in School and Educational Psychology. In consonance, in the first section of this paper, we present action perspectives, selectively based on motivational theories focused on reasons to engage to something, and attempt to answer three basic questions: What motivates students to learn? Who motivates them? How? The second part takes into account the same theoretical frameworks and is devoted to reflect upon the following questions: How to self-motivate? What are the strategies individuals can use to regulate their motivation in the educational context? We hope to provide the reader with information that can be useful to motivate someone to learn as well as to maintain his/her own motivation in an optimal level to facilitate quality of learning. We also expect that this theme will be more disseminated in psychologists' education.

Keywords: learning, self-regulation, motivation, educational psychology.

\section{Resumen}

La motivación es un constructo clave en la Psicología Escolar y Educacional. De esta forma, en este artículo, se presentarán, en la primera parte, líneas de acción, selectivamente basadas en teorías motivacionales que enfocan las razones para el compromiso, teniendo como hilo conductor la búsqueda de respuestas a tres cuestiones básicas: ¿Qué motiva a los alumnos a aprender? ¿Quién los motiva? ¿Y cómo? En la segunda parte, sobre la base de los mismos marcos teóricos, la reflexión será sobre las siguientes cuestiones: ¿Cómo automotivarse? ¿Qué estrategias existen para ayudar a los individuos a que regulen su motivación en el contexto educativo? Se espera proveer al lector con informaciones útiles tanto para motivar a alguien a aprender como para mantener su propia motivación en un estado óptimo y favorecedor del aprendizaje de calidad. Asimismo, la expectativa es que esa temática sea más difundida en la formación de los psicólogos.

Palabras-clave: aprendizaje, autorregulación, motivación, psicología educacional. 
As tarefas conducentes à aprendizagem, que ocorre tanto na escola como ao longo da vida, têm como característica a de exigirem esforço mental, persistência e uso de diversos recursos internos, que incluem estratégias eficazes. Daí se deduz que, para aprender, é imprescindível que os alunos estejam motivados, uma vez que, pelos processos motivacionais, atividades são iniciadas e mantidas (Schunk, Meece, \& Pintrich, 2014). Segundo estes autores, todo o conhecimento acumulado sobre motivação no contexto escolar provém de dados de pesquisas inspiradas em modelos teóricos sociocognitivos, isto é, que privilegiam processos cognitivos diversos, bem como influências do ambiente social.

Autores como Boruchovitch e Bzuneck (2009), Pintrich (2003) e Schunk et al. (2014) apresentaram detalhadamente os diversos modelos teóricos contemporâneos que têm como foco a motivação para aprender. Essa diversidade revela o aspecto fundamental de que a motivação do aluno não consiste numa variável simples, representada por um único fator, de modo que, para efeitos práticos, bastaria considerá-la apenas como presente ou ausente, apenas com variações em grau. Pelo contrário, motivação é um constructo multidimensional e complexo. Assim, à questão do que motiva os alunos, abre-se uma lista de diversos fatores identificados pelos teóricos, de modo que o propósito de motivar alunos para aprender dependerá da consideração de todos esses fatores (Pintrich, 2003).

Como a motivação é um construto-chave na Psicologia, neste artigo serão apresentadas, na primeira parte, linhas de ação seletivamente baseadas nas teorias de metas de realização, da autodeterminação e de expectativa-valor, que focalizam razões para o engajamento. Também foi aqui escolhida a autoeficácia como constructo motivacional representativo de autopercepção de capacidade. Todas essas abordagens motivacionais têm como fio condutor a busca de resposta a três questões básicas: $\mathrm{O}$ que motiva os alunos a aprender? Quem os motiva? E como? Já a segunda parte do artigo será devotada ao atendimento das seguintes questões: Uma pessoa pode automotivarse? Em caso afirmativo, quais estratégias estão disponíveis para que os indivíduos consigam autorregular a sua motivação?

Dessa forma, a expectativa é de prover o leitor de informações que possam ser úteis tanto para motivar alguém a aprender quanto para manter a sua própria motivação num estado ótimo, que conduza a uma aprendizagem de qualidade. Acredita-se que essas informações, certamente, serão úteis para instrumentalizar a escola, os psicólogos escolares, os psicopedagogos e os educadores a respeito de como a regulação motivacional dos indivíduos no contexto educativo ocorre ou pode ser facilitada. Considera-se também importante que esses temas possam ser mais difundidos em cursos de formação de psicólogos.

\section{Razões para o engajamento: as metas de realização}

A teoria de metas de realização (Achievement Goals Theory) tem-se revelado como um dos referenciais da motivação mais pesquisados na Psicologia Educacional (Conley, 2012). Não se trata, porém, de objetivos ou metas que a pessoa busca atingir, como foram consideradas, por exemplo, nos estudos sobre metas sociais (Wentzel, 2000), na teoria do estabelecimento de metas (Locke \& Latham, 2002), ou sobre metas de vida (por exemplo, Bilde, Vansteenkiste, \& Lens, 2011), todas elas também com função motivacional. Ao contrário, uma meta de realização consiste num propósito ou razão, um porquê de a pessoa se envolver numa atividade, e se compõe de um conjunto integrado de percepções, crenças, atribuições e reações afetivas diante de sucesso ou de fracasso, e tem como foco a competência. Assim, Hulleman, Schrager, Bodmann, \& Harackiewicz (2010) definiram essas metas como "representações cognitivas que orientam o comportamento para um estado final relacionado com competência, no qual a pessoa está empenhada, quer para atingir, quer para evitar algum resultado" (p. 423).

$\mathrm{Na}$ fase inicial dos estudos desse constructo, os autores (por ex., Ames, 1992) discriminaram duas 
metas no contexto das realizações acadêmicas. A primeira era denominada, variando conforme o autor, de meta de domínio, meta aprender, ou tarefa, que se referia ao propósito ou objetivo de, com o cumprimento das tarefas escolares, desenvolver competência ou chegar ao domínio da tarefa. Como característica adicional, tais alunos valorizam o próprio esforço, atribuindo eventuais fracassos à sua falta ou a estratégias ineficazes.

Já a meta de performance (também denominada meta ego, ou de capacidade relativa) denotava o propósito de envolver-se com os estudos para demonstrar capacidade/competência ou aparecer como melhor que os outros, ou ainda não aparecer como incapaz/incompetente ou pior que os outros. Daí o termo intraduzível de performance, que indica a realização visível, pública e apreciada diante de uma plateia real ou imaginária.

\section{Efeitos sobre engajamento acadêmico}

Questão crítica é saber em que medida cada uma dessas metas responde por efeitos diferenciados no engajamento acadêmico e no desempenho, quando se trata de alunos. De acordo com os estudos revisados por Senko e Hulleman (2013), a meta domínio-aproximação aparece como particularmente adaptadora. Alunos que a adotam revelam engajamento da melhor qualidade nos estudos, consideram os conteúdos mais interessantes, são mais perseverantes, pedem ajudas oportunas e usam de estratégias eficazes de aprendizagem e de autorregulação. Essa seria, portanto, a orientação motivacional mais desejável e a ser preferencialmente implementada na escola e por parte dos pais com seus filhos. Em contraste, a meta performance-aproximação, quando medida em termos de comparação social (ser melhor que
Essa bifurcação de metas domínio versus performance foi mantida em pesquisas até o final dos anos 1990, quando se descobriu a necessidade de se desdobrar a meta performance em performance-aproximação (propósito de aparecer competente ou melhor que os outros) e performance-evitação (propósito de não aparecer como incompetente ou pior que os outros). Posteriormente, a mesma distinção foi aplicada à meta domínio, considerando-se a meta domínioaproximação, cujo foco é o domínio e plena compreensão dos conteúdos e, por outro lado, domínio-evitação, quando o propósito é evitar erros e falhas nas aprendizagens. Portanto, hoje se admitem quatro metas de realização distintas que, operacionalizadas em escalas, consolidaram-se na fórmula 2 x 2 (por ex., Elliot, \& Murayama, 2008).

os outros) também prediz aplicação de estratégias de profundidade, bom desempenho nas aulas e notas altas. Essa relação positiva, porém, não foi constatada quando essa meta era medida em termos de desejo de aparecer como inteligente, pois, nesse caso, tem-se relacionado com menos interesse pelas aprendizagens em si. Já as duas metas de evitação, domínio-evitação e performance-evitação estão em geral associadas a resultados desadaptadores como baixo interesse, ansiedade e, por fim, notas mais baixas (Senko \& Hulleman, 2013). Convém assinalar que, embora as metas domínio e performance-aproximação sejam avaliadas como distintas, alunos as adotam, frequentemente, de forma combinada, usufruindo das vantagens associadas a cada uma delas.

\section{Influências socioambientais na adoção de metas}

A adoção preferencial pelos alunos de uma ou outra meta de realização resulta, além de outros fatores possíveis de natureza social ou intrapessoal, das suas experiências na escola e, em particular, em sua sala de aula, com cada professor. Os alunos tendem a perceber um clima psicológico 
em suas classes, que representa uma estrutura definida de metas, que consiste de políticas e práticas adotadas pelos professores e pela escola como um todo, associadas a mensagens explícitas que são comunicadas aos alunos (Ames, 1992; Anderman, Anderman, Yough, \& Gimbert, 2010). Em poucas palavras, professores diferentes, com suas ações e verbalizações, criarão estruturas que, como efeito probabilístico, levarão seus alunos a abraçarem uma ou outra meta de realização, com suas consequências comportamentais e afetivas.

$\mathrm{Na}$ prática, a orientação às duas formas de meta performance será fomentada quando o clima de sala de aula ou da escola se caracterizar pela prática de comparação social ou de classificação dos alunos por capacidade, o que inclui a publicidade dos melhores e a demonstração pública do saber. Em contraposição, têm sido arroladas como âncoras de ações docentes promotoras da meta domínio a apresentação das tarefas como desafiadoras, revestidas de valor e promotoras de interesse, o reconhecimento do esforço como causa de sucesso e a utilização de padrões autorreferenciados nas avaliações (para mais detalhes, ver, por ex., Ames, 1992; Guimarães, 2009; Schunk et al., 2014). Além desse conjunto, contribuirão para a estrutura da meta domínio, em classe, variáveis como apoio dos professores, respeito, além de promoção de interações positivas entre os próprios alunos (Patrick, Turner, Meyer, \& Midgley, 2003).

\section{Razões para o engajamento: motivação intrínseca ou extrínseca}

Outra linha de estudos que focalizam razões para o engajamento acadêmico tem como referencial a teoria da autodeterminação (Deci \& Ryan, 2004). No passado, autores consideravam apenas a distinção clássica entre motivação intrínseca e extrínseca. É intrinsecamente motivada a pessoa que exerce uma ação apenas por interesse pessoal e porque a atividade lhe dá prazer. Já uma pessoa será extrinsecamente motivada quando praticar uma ação movida por recompensa externa à vista, ou para evitar punição, ou simplesmente por pressão ou obrigação.

Deci e Ryan (2004) construíram a teoria da autodeterminação, superando a polarização simples de motivação, seja intrínseca ou extrínseca. Em primeiro lugar, esses autores reconhecem que as pessoas, em geral, cumprem inúmeras tarefas não por motivação intrínseca, mas porque são obrigadas ou a conseguir recompensas ou evitar punições. Melhor do que estar desmotivado é agir em função desses motivadores extrínsecos. Entretanto, para os autores da teoria não é fatalmente imutável a condição de os indivíduos agirem por motivação extrínseca. Todo ser humano tem uma tendência inata para o autocrescimento, mediante o processo de interiorização de suas experiências, em direção a sucesso pessoalmente gratificante, bem-estar e integração social, o que significa evoluir para tipos mais autorregulados de motivação.

Dessa forma, os autores da teoria propuseram que, afora os casos de desmotivação, a própria motivação extrínseca se desdobra em quatro níveis qualitativamente distintos, começando pela motivação por pura regulação externa, equivalente à clássica motivação extrínseca (por recompensas ou punições), seguida da regulação introjetada, na qual já se configura certa interiorização, mas ainda com pressão psicológica de origem interna, pois as ações são exercidas para se evitar culpa ou vergonha ou por outro motivo autorreferenciado. Em síntese, essas duas primeiras formas de regulação, embora distintas entre si, pertencem à categoria de motivação controlada.

Ao se avançar na descrição do continuum da autorregulação, aparece a motivação extrínseca por identificação, um estado em que a pessoa terá internalizado os valores sociais associados à ação, identificando-se com eles. E, por último, vem a regulação identificada, em que os valores são endossados por serem congruentes com os próprios valores da pessoa. Já fora do espaço 
caracterizado por motivação extrínseca, com seus quatro níveis de regulação já descritos, situa-se a motivação intrínseca, agora plenamente autotélica. Um conceito importante presente nesse continuum é o de motivação autônoma, que se configura tanto na motivação intrínseca como nas formas identificadas e integradas da motivação extrínseca (Deci \& Ryan, 2004). Motivação autônoma tem sido associada com interesse, satisfação e engajamento, incluindo atenção, esforço, persistência na tarefa, permanência na escola e nível de desempenho (Reeve, 2004).

Em cada ser humano, embora sejainata a tendência para os estados motivacionais autorregulados, ela pode tanto ser obstaculizada como promovida e facilitada por pessoas significativas do ambiente (Deci \& Ryan, 2004), que incluem, no caso de alunos, sobretudo pais e professores. A influência dessas pessoas significativas ocorrerá quando elas se prestarem a atender três necessidades psicológicas básicas dos indivíduos: de relacionamento, competência e autonomia.

A necessidade de relacionamento será atendida quando a pessoa se sentir vinculada a pessoas significativas, objeto de cuidados e com senso de pertencimento. Necessidade de competência refere-se à pessoa sentir-se eficaz nas interações com seu meio, o que, na escola, implica que o aluno se avalie como bem-sucedido nas tarefas de aprendizagem. Professores contribuirão para a satisfação dessa necessidade ao oferecerem desafios em nível adequado às capacidades dos alunos, mostrarem reconhecimento pelos bons resultados e evitarem atribuir erros e fracassos à falta de capacidade.

Por último, quando for atendida a necessidade de autonomia (que não deve ser confundida com independência), a pessoa percebe-se origem ou fonte de seu próprio comportamento e assim age por interesse, por escolha pessoal e pela integração de valores (Deci \& Ryan, 2004). Entre as estratégias que promovem o senso de autonomia, na escola, podem mencionar-se a de permitir que os alunos, em certos casos, tenham liberdade de fazer escolhas; evitar o uso de linguagem controladora, do tipo "vocês devem..."; e sempre argumentar pelo valor e importância das aprendizagens. Um relato completo de todas as ações docentes que compõem o estilo promotor de autonomia, segundo vários autores, pode ser encontrado, por exemplo, em Bzuneck e Guimarães (2010).

\section{Razão para o engajamento: valorização}

A valorização subjetiva de uma atividade tem sido amplamente documentada na literatura como importante fator motivacional (Schunk et al., 2014), já destacado nas duas abordagens anteriormente descritas. Em sua teoria de expectativa-valor, Wigfield e Eccles (2002; ver também Eccles, 2005) argumentaram que a valorização de uma atividade tem considerável impacto quando se trata de fazer escolhas, seja no contexto escolar ou em qualquer situação da vida. Entretanto, Wigfield e Eccles trouxeram contribuição valiosa ao proporem que a valorização de determinada tarefa se reveste de quatro aspectos ou componentes. Assim, existe valor de realização (ou de importância pessoal), valor intrínseco, valor instrumental e custo.
O valor de realização ou de importância pessoal consiste em se apreciar a relevância de se engajar em um curso de ações porque elas contribuem para confirmar aspectos salientes do self, que incluem, entre outros, a identidade de gênero. Além disso, terá valor de realização a atividade que aparecer como capaz de atender às necessidades psicológicas básicas de autonomia, competência e relacionamento, como foi proposto pela teoria da autodeterminação (Deci \& Ryan, 2004).

Como segundo aspecto, será valorizada uma atividade que for vista como pessoalmente interessante ou porque causa satisfação e prazer, um conceito igualmente presente na teoria da autodeterminação ao tratar da motivação intrínseca. Já o valor instrumental ou de utilidade 
refere-se à percepção da relação das tarefas com metas futuras, próximas ou distantes, tais como ser socialmente aceito, fazer outros cursos, ou ter suecesso numa carreira profissional. Desse modo, o indivíduo se envolverá em determinadas tarefas, mesmo quando não sejam interessantes, por considerar que sua realização é meio para se atingir algum objetivo mais à frente, o que inclui até metas de vida. Esse último aspecto foi amplamente explorado em estudos com referencial na teoria de perspectiva de tempo futuro (por ex., Bilde et al., 2011). Por último, o valor de custo resulta da ponderação entre a execução da atividade e as exigências inerentes a ela em termos de esforço e tempo, e até o preço emocional.

\section{Crenças de autoeficácia: imprescindivel fator motivacional}

Uma condição crítica para o engajamento numa atividade consiste em a pessoa acreditar ter competência necessária para executá-la. Bandura (1997), que, desde os anos 1970, havia introduzido esse conceito na literatura motivacional, conceituou autoeficácia como "crenças das pessoas em suas capacidades para organizar e executar cursos de ação necessários para alcançar certos tipos de desempenho" (p. 3). Apreciável volume de pesquisas empíricas (ver, por ex., Azzi \& Polydoro, 2006; Pajares \& Olaz, 2008; Schunk et al., 2014), desde as do próprio Bandura, tem documentado o papel motivacional da autoeficácia em diversas áreas de atividade humana, como cuidados com a saúde, esportes, educação e empreendedorismo. Tem sido consistente o dado de que a crença nas próprias capacidades para agir é poderoso fator de influência sobre o estabelecimento de metas, aplicação de esforço, persistência diante de dificuldades e resiliência após fracassos. Inversamente, quando a pessoa reconhecer sua incapacidade ou tiver dúvidas acentuadas de suas capacidades para determinada ação em particular, cessará o empenho, pois, nesse caso, nem interesse pessoal, nem o senso de obrigação e nem a antevisão de objetivos de valor terão força motivacional suficiente.

Entretanto, o desenvolvimento de crenças robustas de autoeficácia depende de determinados fatores. Bandura (1997) propôs serem quatro as fontes que dão origem a essas crenças. A primeira e mais decisiva consiste em a pessoa ter passado por experiências de êxito em tarefas semelhantes. Tais experiências dão apoio a que pessoa conclua que, se já conseguiu bons resultados no passado, tem capacidade para exercer mais essa nova atividade desafiadora também com êxito. Influências sociais provêm de outras pessoas como alimentadoras de autoeficácia, quer enquanto modelos, quer por verbalizações persuasivas. Isto é, a observação de pessoas de nível similar de capacidade e que foram bem-sucedidas facilita a crença do indivíduo quanto à própria capacidade. Da mesma forma, a autoeficácia será alimentada quando lhe forem passadas expressões verbais de confiança em sua capacidade. Por último, a identificação de estados afetivos negativos induz a dúvidas quanto à autoeficácia, enquanto que a de afetos positivos a favorece. Bandura ainda observou que qualquer dessas fontes só exerce influência mediante um processo de ponderação e julgamento da pessoa, o que basicamente varia conforma as situações.

Em síntese, as teorias sociocognitivas aqui descritas demonstram que os alunos podem apresentar tipos de motivação qualitativamente distintos, em termos de razões específicas e de crenças, que têm efeitos diferenciados sobre o engajamento, a afetividade e o desempenho acadêmico. A orientação à meta de realização domínio e à motivação autônoma apareceram como mais associadas à intensidade comportamental nas aprendizagens e à qualidade emocional. Valorização das atividades propostas apareceu como variável crucial nesses dois modelos e, mais especificamente, na teoria da expectativavalor. Por último, ficou demonstrado como a autoeficácia é fator decisivo para a motivação. Ao mesmo tempo, foram descritas estratégias 
com as quais professores ou outros agentes na educação podem contribuir para manter e fortalecer os tipos de motivação de qualidade superior, ao exercerem influência sobre o que motiva as pessoas. Na sequência, tendo como referenciais os modelos teóricos anteriormente

\section{A autorregulação da motivação}

Wolters (2003) e Schwinger, Steinmayr, e Spinath (2009) mencionam que, se é abundante a investigação de como variáveis motivacionais afetam a regulação de estratégias cognitivas e metacognitivas, tem havido menos ênfase na busca da compreensão de como o aluno regula a sua própria motivação. Ora, autores como Pintrich (2000; 2004), Wolters (2003; 2011) e Zimmerman (2013) argumentaram que os alunos também podem regular sua motivação e afetos, da mesma forma como podem regular suas cognições, seus comportamentos e o próprio ambiente.

A autorregulação motivacional, enquanto descritos, serão apresentadas, a partir do conceito de autorregulação da motivação, as principais estratégias para a pessoa retomar uma motivação debilitada e nela se manter, principalmente no contexto educativo.

faceta da autorregulação da aprendizagem, foi definida por Wolters $(2003$; 2011) como uma forma de controle relativamente consciente da própria motivação, a serviço da retomada ou do aumento do esforço e da persistência. Dessa forma, implica, por parte do indivíduo, em conhecimento da própria motivação, que se expressa num nível metacognitivo de reflexão sobre si próprio e sobre as condições das tarefas que deve enfrentar, bem como do contexto. Em outras palavras, essa forma específica de autorregulação consiste numa intervenção pessoal deliberada por parte do aluno na gestão dos próprios processos motivacionais.

\section{Quando se faz necessária a autorregulação da motivação}

Winne (2010) defendeu que toda autorregulação é inerentemente contextual, isto é, esse processo específico será ativado frente a características específicas da situação e da tarefa. Em relação às aprendizagens escolares, podem-se vislumbrar ao menos duas situações em que a autorregulação da motivação se torna oportuna e até imperiosa. A primeira consiste na mudança para um ambiente de aprendizagem menos estruturado, que começa já na passagem para a segunda fase do Ensino Fundamental e, de modo mais acentuado, por ocasião do ingresso no Ensino Superior, que exige que o aluno seja pessoalmente mais responsável pelas atividades de aprendizagem (Zimmerman \& Martinez-Pons, 1986). A outra situação, que também estaria implícita na primeira, engloba todos os casos em que uma pessoa se defrontar sozinha com a exigência, por exemplo, de estudar para uma prova, para um concurso, ou simplesmente de fazer o dever de casa ou de manter-se atento e participativo numa aula expositiva.

Os processos motivacionais no ser humano não atingem por igual todas as áreas e tarefas e, mesmo quando ativados para uma área ou tarefa, não são necessariamente estáveis, mas sofrem oscilações. No contexto escolar, por exemplo, não é raro que tarefas apareçam como tediosas, desinteressantes, não desafiadoras, sem um significado visível, ou que sejam vistas simplesmente como difíceis. Nesses casos, a desmotivação pode instalar-se e nem a obrigação de cumprir ou de concluir a tarefa será suficiente para mobilizar o esforço. Essa condição psicológica, com suas consequências, revelou-se num estudo clássico de Wolters (1998), que apresentou aos alunos de sua amostra três diferentes situações: conteúdo irrelevante, conteúdo difícil e conteúdo tedioso. Descobriu 
diferenças nas respostas dos alunos em diversas medidas de motivação, em função dessas três situações. Alguns estudantes interrompiam o processo de aprender e, em última instância, chegavam a abandonar a escola ao se defrontarem com dificuldades que lhes parecem insuperáveis.

Ainda em relação com tarefas acadêmicas, e isso em qualquer nível de escolaridade, um elemento complicador se insinua por conta de interferência motivacional (Fries \& Dietz, 2007; Hofer, 2010), ou seja, quando a pessoa é afetada por eventos ou estímulos concorrentes que distraem do foco. Trata-se, sobretudo, de atividades normalmente muito atraentes e pessoalmente valorizadas, que incluem a de sair com os amigos, entreter-se com o smartphone, assistir televisão, entre outras, do que resulta um conflito entre a exigência de execução da tarefa e aquelas tentações advindas do contexto. Nesses casos, surge a necessidade de a pessoa optar por não ceder a essas tentações de prazer imediato e, em seu lugar, praticar o adiamento da gratificação (Bembenutty \& Karabenick, 2004), o que exige autorregulação da motivação. Tal problema foi identificado, como exemplo, no estudo de Duckworth, White, Matteucci, Shearer, e Gross (2016), que partiram do fato constatado de que alguns alunos desejam sinceramente sair-se bem na escola, mas são incapazes de regular seu comportamento de modo que atinjam aqueles objetivos desejados, por se mostrarem ineficazes em evitar atividades chamativas e concorrentes. Assim, revelam um hiato entre seus desejos acadêmicos de longo prazo e suas ações mais próximas, carecendo de estratégias de autocontrole com as quais possam cobrir aquele hiato.

Em síntese, se motivação faz ações acontecerem, são inúmeras as situações em que os fatores motivacionais para o envolvimento nas tarefas de aprendizagem podem estar inertes ou não ativados naquela pessoa, ou sobrepujados por motivação para fazer outra coisa. Por isso, em todos os casos de ausência de pessoas ou de eventos externos que promovam ou ativem a devida motivação, resta que a própria pessoa adote proativamente estratégias de autorregulação dos processos motivacionais, que autores como Zimmerman (2002) denominaram como exercício de controle volitivo.

Pintrich (2003) expôs muito apropriadamente uma lista do que motiva os alunos, a qual inclui as crenças de autoeficácia, interesse, expectativas e metas, e valorização. De acordo com diversos estudos (por ex., Paulino, Sá, \& Silva, 2015; Wolters, 2003; 2011; Wolters, \& Benzon, 2013), o exercício da autorregulação da motivação, pela própria pessoa, também consiste na exploração de alguma dessas variáveis motivacionais. Dessa forma, dada à variedade de situações que envolvem as tarefas a cumprir, bem como diferenças individuais em termos de motivação, acham-se disponíveis estratégias específicas para a regulação de sua motivação e que, sem a pretensão de representarem uma cobertura exaustiva, serão brevemente descritas.

\section{As estratégias de autorregulação da motivação}

Regulação pelo interesse situacional. Particularmente nos casos de tarefas tediosas tem sido indicada essa estratégia, que consiste em ativar a motivação intrínseca por uma tarefa, buscando torná-la interessante, o que se conseguiria, por exemplo, transformando-a num jogo (Paulino et al., 2015; Sansone, Weir, Harpster, \& Morgan, 1992; Wolters 1998; 2003; Wolters \& Rosenthal, 2000).
Regulação pelo refinamento da significância pessoal. Evocar o valor como significado da tarefa, especialmente o valor instrumental de sua utilidade para se atingirem objetivos mais avançados, como novos cursos ou profissão futura, ou até para objetivos mais próximos, como conseguir boas notas ou ser reconhecido (Paulino et al., 2015; Wolters, 1998).

Regulação pelas metas de realização. Retomar 
o foco na orientação à meta domínio, mediante diálogo interno, pelo qual se reitere principalmente o grande propósito de crescer intelectualmente e dominar os conteúdos (Wolters, 1998).

Regulação pela autoconsequência ou autorreforçamento. A estratégia consiste em prometer para si próprio, em função do cumprimento de certas tarefas, sejam elas particularmente penosas ou desinteressantes, recompensas externas, como descansar, ouvir música, entrar na rede social, o que terá papel de autorreforço positivo antecipado. Vale inclusive o compromisso de privar-se de uma atividade gratificante ou de um comestível apetitoso, para casos em que a tarefa tiver sido abandonada ou interrompida (Dembo, 2000; Duckworth et al., 2016; Paulino et al., 2015; Wolters, 1998; 2003; Wolters \& Rosenthal, 2000; Zimmerman \& Martinez-Pons, 1986).

Regulação da autoeficácia. Especialmente diante de dificuldades maiores de certas tarefas, alunos podem sofrer abalo na sua crença de autoeficácia, o que paralisaria o esforço. Positivamente, a autoeficácia será alimentada, nesses casos, com o uso de diálogo interno, do tipo "eu sei que posso realizar essa tarefa", como foi sugerido por Bandura (1997). Para ser eficaz, porém, a verbalização deve ter apoio na evocação de situações passadas de superação de dificuldades, ou seja, experiências de domínio. Em particular, também contribui muito a verificação do próprio progresso, uma vez que toda percepção de progresso anterior contém mensagem alimentadora de autoeficácia (Schunk \& Zimmerman, 2008). Na mesma linha, o parcelamento de uma tarefa maior em metas próximas sucessivas, específicas e de nível adequado de desafio com maior probabilidade proporcionará experiências seguidas de sucesso, que alimentam a autoeficácia e até a motivação intrínseca (Bandura \& Schunk, 1981).

Regulação pela estruturação do contexto. Com o objetivo de diminuir a probabilidade de desvio do foco ou até de desistência da realização da tarefa, essa forma de regulação é alcançada por meio da aplicação de estratégias como, por exemplo, a tentativa de redução das distrações pela busca de contextos que favoreçam a concentração (Wolters, 1998; Wolters \& Benzon, 2013).

Numa frase lapidar, Zimmerman (2000) sintetizou que alunos bem-sucedidos são aqueles que se engajam na autorregulação de sua motivação, das cognições, do ambiente e do comportamento. O engajamento na autorregulação da motivação, porém, não ocorre, normalmente, de forma espontânea, mas depende de certas condições intrapessoais e contextuais. Em primeiro lugar, exige-se que a pessoa tome consciência de que sua motivação para certa atividade se encontra em declínio, ao identificar-se, por exemplo, como entediado ou com autoeficácia reduzida (Wolters, 2011; Wolters \& Benzon, 2013). Na sequência a esse automonitoramento, restabelecer a própria motivação será uma tarefa que exige tomada de decisão e esforço mental. Por isso, para que um aluno a exerça, não pode achar-se totalmente desmotivado, mas deve ainda manter certo nível motivacional prévio, consistindo, por exemplo, numa orientação subjacente à meta domínio ou mesmo à meta de vencer uma competição, uma forma de performance-aproximação. Por sua natureza, metas de realização são constructos relativamente estáveis nos indivíduos e, por isso, têm aparecido com valor de predição do uso de autorregulação da própria motivação (Paulino et al., 2015; Wolters \& Benzon, 2013; Wolters \& Rosenthal, 2000).

Por outro lado, numa perspectiva social cognitiva, a autorregulação acadêmica e da motivação tem origens sociais e, ao mesmo tempo, resulta de um processo desenvolvimental que envolve interações específicas entre o aluno e o contexto. Schunk e Zimmerman (1997; ver também Zimmerman, 2013), na esteira da teoria social cognitiva de Bandura, apresentaram um modelo desse desenvolvimento, que ocorre por quatro etapas, o que tem sido comprovado em inúmeros estudos (Zimmerman, 2002). Embora os autores aí contemplem diretamente a autorregulação da aprendizagem, o modelo é igualmente aplicável, segundo Wolters (2011), à dimensão específica da autorregulação da motivação. 
Numa descrição sucinta desses níveis, o inicial e também o mais crítico consiste no processo de modelação. Isto é, a primeira condição consiste em o aluno observar reiteradamente pessoas significativas (como professores, colegas ou pais), que revelem deter conhecimentos de diversas estratégias de autorregulação e que as pratiquem. Ainda nessa fase, o aluno poderá identificar que os modelos valorizam as tarefas e nelas são persistentes, com provável alto impacto positivo sobre sua própria motivação. O nível seguinte consiste na emulação, ou seja, o aluno receberá orientação, apoio e feedback por parte de pessoas competentes que acompanharão sua prática das habilidades anteriormente observadas e já interiorizadas. Numa terceira fase, guiado por representações mentais dos padrões desenvolvidos nas fases anteriores, o aluno exercerá autocontrole, praticando as habilidades de modo automatizado e exercendo o autorreforçamento. Por fim, ele atingirá o nível final em que poderá adaptar, de modo sistemático e autônomo, conforme exigências pessoais e situacionais cambiantes, os conhecimentos e as habilidades adquiridas. Aí atuarão como motivadores a orientação a metas e as crenças de autoeficácia, com pouca ou nenhuma orientação por parte de pessoas significativas.

$\mathrm{O}$ atendimento dessa sequência de fases serve como referencial para as pessoas que, em razão de sua atuação profissional, aspirarem a que seus alunos desenvolvam autorregulação da aprendizagem e da motivação. Em particular, como a literatura tem demonstrado, será imprescindível a apresentação de modelos e de outras ajudas destinadas a que os alunos se tornem competentes em se automonitorar e em adotar a estratégia de autorregulação da motivação mais funcional em cada situação.

Cabe mencionar que as estratégias de autorregulação da motivação têm como finalidade principal melhorar e assegurar a motivação e não o desempenho em si. Entretanto, elas medeiam a relação da motivação com o desempenho, na medida em que aumentam a probabilidade de que as pessoas invistam esforços para o alcance das metas de aprendizagem. Estratégias de autorregulação motivacional têm por objetivo imediato a retomada de uma motivação em crise, o aumento da persistência na tarefa e até a diminuição de autorreações defensivas e reações emocionais adversas ao sucesso acadêmico.

Esforços nesse sentido têm-se revelado muito frutíferos, pois pesquisas mostram que muitos alunos não se engajam em atividades acadêmicas, ou escolares, não porque têm dificuldades cognitivas para realizá-las, mas por problemas motivacionais dos quais sequer têm consciência ou não sabem como lidar com eles (Boruchovitch, 2001). Em última instância, investimentos em intervenções voltadas à promoção da capacidade de autorregular a motivação, bem como orientações especificas aos estudantes sobre as principais estratégias de regulação da motivação muito contribuirão para a melhoria das aprendizagens. Por fim, destaca-se a necessidade e a relevância de que psicólogos escolares, psicopedagogos e professores sejam capacitados para atuarem nessa direção.

\section{Referências}

Ames, C. (1992). Classrooms: Goals, structures, and student motivation. Journal of Educational Psychology, 84(3), 261-271. doi: 10.1037/0022-0663.84.3.261

Anderman, E. M., Anderman, L. H., Yough, M. S., \& Gimbert, B. G. (2010). Value-added models of assessment: Implications for motivation and accountability. Educational Psychologist, 45(2), 123-137. doi: 10.1080/00461521003703045

Azzi, R. G., \& Polydoro, S. A. J. (2006). Auto-eficácia em diferentes contextos. Campinas, SP: Alínea.
Bandura, A. (1997). Self-efficacy: The exercise of control. New York: W.H. Freeman and Co.

Bandura, A., \& Schunk, D. H. (1981). Cultivating competence, self-efficacy, and intrinsic interest through proximal selfmotivation. Journal of Personality and Social Psychology, 41(3), 586-598. doi: 10.1037/0022-3514.41.3.586

Bembenutty, H., \& Karabenick, S. A. (2004). Inherent association between academic delay of gratification, future time perspective, and self-regulated learning. 
Educational Psychology Review, 16(1), 35-57. doi: 10.1023/B:EDPR.0000012344.34008.5c

Bilde, J., Vansteenkiste, M., \& Lens, W. (2011). Understanding the association between future time perspective and selfregulated learning through the lens of self-determination theory. Learning and Instruction, 21(3), 332-344. doi: 10.1016/j.learninstruc.2010.03.002

Boruchovitch, E. (2001). Dificuldades de aprendizagem, problemas motivacionais e estratégias de aprendizagem. In F. F. Sisto, E. Boruchovitch, L. D. T. Fini, R. P. Brenelli, \& S. C. Martinelli (Orgs.). Dificuldades de aprendizagem no contexto psicopedagógico (pp. 40-59). Petrópolis, RJ: Vozes.

Boruchovitch, E., \& Bzuneck, J. A. (2009). A motivação do aluno: contribuições da Psicologia contemporânea. Petrópolis, RJ: Vozes.

Bzuneck, J. A., \& Guimarães, S. E. R. (2010). A promoção da autonomia como estratégia motivacional na escola: uma análise teórica e empírica. In E. Boruchovitch, J. A. Bzuneck, \& S. E. R. Guimarães (Orgs.). Motivação para aprender: aplicações no contexto educativo (pp. 43-70). Petrópolis, RJ: Vozes.

Conley, A. M. (2012). Patterns of motivation beliefs: Combining achievement goal and expectancy-value perspectives. Journal of Educational Psychology, 104(1), 32-47. doi: 10.1037/a0026042

Deci, E. L., \& Ryan, R. M. (2004). Handbook of selfdetermination research. Rochester, NY: The University Rochester Press.

Dembo, M. H. (2000). Motivation and learning strategies for college success. Mahwah, NJ: Lawrence Erlbaum.

Duckworth, A. L., White, R. E., Matteucci, A. J., Shearer, A., \& Gross, J. J. (2016, April). A stitch in time: Strategic selfcontrol in high school and college students. Journal of Educational Psychology, 108(3), 329-341. doi: 10.1037/ edu0000062

Eccles, J. S. (2005). Subjective task value and the Eccles et al. model of achievement-related choice. In A. J. Eliot \& C. S. Dweck (Eds.), Handbook of competence and motivation (pp. 105-121). London: The Guilford Press.

Elliot, A. J., \& Murayama, K. (2008). On the measurement of achievement goals: Critique, illustration, and application. Journal of Educational Psychology, 100(3), 613-628. doi: 10.1037/0022-0663.100.3.613

Fries, S., \& Dietz, F. (2007). Learning with temptations present: The case of motivational interference. Journal of Experimental Education, 76(1), 93-112. doi: 10.3200/ JEXE.76.1.93-112

Guimarães, S. É. R. (2009). A organização da escola e da sala de aula como determinante da motivação intrínseca e da meta aprender. In E. Boruchovitch, \& J. A. Bzuneck (Orgs.). A motivação do aluno: contribuições da Psicologia contemporânea (pp. 78-95). Petrópolis, RJ: Vozes.

Hofer, M. (2010). Adolescents' development of individual interests: A product of multiple goal regulation?
Educational Psychologist, 45(3), 149-166. doi: 10.1080/00461520.2010.493469

Hulleman, C. S., Schrager, S. M., Bodmann, S. M., \& Harackiewicz, J. M. (2010, May). A meta-analytic review of achievement goal measures: Different labels for the same constructs or different constructs with similar labels? Psychological Bulletin, 136(3), 422-449. doi: 10.1037/a0018947

Locke, E. A., \& Latham, G. P. (2002, September). Building a practically useful theory of goal setting and task motivation. A 35-year odyssey. The American Psychologist, 57(9), 705-717. doi: 10.1037/0003-066X.57.9.705

Pajares, F., \& Olaz, F. (2008). Teoria social cognitiva e autoeficácia: uma visão geral. In A. Bandura, R. G. Azzi, \& S. A. J. Polydoro (Orgs.). Teoria cognitiva: conceitos básicos (pp. 97-114). Porto Alegre: Artmed.

Patrick, H., Turner, J. C., Meyer, D. K., \& Midgley, C. (2003). How teachers establish psychological environments during the first days of school: Associations with avoidance in mathematics. Teachers College Record, 105(8), 1521-1558. doi: 10.1111/1467-9620.00299

Paulino, P., Sá, I., \& Silva, A. L. (2015). Autorregulação da motivação: Crenças e estratégias de alunos portugueses do $7^{\circ}$ ao $9^{\circ}$ ano de escolaridade. Psicologia: Reflexão e Crítica, 28(3), 574-582. doi: 10.1590/16787153.201528316

Pintrich, P. R. (2000). The role of goal orientation in selfregulated learning. In M. Boekaerts, P. R. Pintrich, \& M. Zeidner (Eds.), Handbook of self-regulation (pp. 451-502). San Diego, CA: Academic Press. doi: 10.1016/B978012109890-2/50043-3

Pintrich, P. R. (2003). A motivational science perspective on the role of student motivation in learning and teaching contexts. Journal of Educational Psychology, 95(4), 667686. doi: $10.1037 / 0022-0663.95 .4 .667$

Pintrich, P. R. (2004). A conceptual framework for assessing motivation and self-regulated learning in college students. Educational Psychology Review, 16(4), 385-407. doi: 10.1007/s10648-004-0006-x

Reeve, J. (2004). Self-determination theory applied to educational settings. In E. L. Deci, \& R. M. Ryan (Orgs.). Handbook of self-determination research (pp. 183-203). Rochester, NY: University of Rochester Press.

Sansone, C., Weir, C., Harpster, L., \& Morgan, C. (1992, September). Once a boring task always a boring task? Interest as a self-regulatory mechanism. Journal of Personality and Social Psychology, 63(3), 379-390. doi: 10.1037/0022-3514.63.3.379

Schunk, D. H., Meece, J. L., \& Pintrich, P. R. (2014). Motivation in education: Theory, research, and applications (4th ed.). Boston, Mass.: Pearson.

Schunk, D. H., \& Zimmerman, B. J. (1997). Social origins of self-regulatory competence. Educational Psychologist, 32(4), 195-208. doi: 10.1207/s15326985ep3204_1

Schunk, D. H., \& Zimmerman, B. J. (2008). Motivation and 
self-regulated learning: Theory, research, and applications. Aarhus: Lawrence Erlbaum Associates.

Schwinger, M., Steinmayr, R., \& Spinath, B. (2009). How do motivational regulation strategies affect achievement: Mediated by effort management and moderated by intelligence. Learning and Individual Differences, 19(4), 621-627. doi: 10.1016/j.lindif.2009.08.006

Senko, C., \& Hulleman, C. S. (2013). The role of goal attainment expectancies in achievement goal pursuit. Journal of Educational Psychology, 105(2), 504-521. doi: $10.1037 / \mathrm{a} 0031136$

Wentzel, K. R. (2000, January). What Is It That I'm Trying to Achieve? Classroom Goals from a Content Perspective. Contemporary Educational Psychology, 25(1), 105-115. doi: 10.1006/ceps.1999.1021

Wigfield, A., \& Eccles, J. S. (2002). The development of competence beliefs, expectancies for success, and achievement values from childhood through adolescence. In A. Wigfield, \& J. S. Eccles (Eds.), Development of achievement motivation (pp. 91-120). New York: Academic Press. doi: 10.1016/B978-012750053-9/50006-1

Winne, P. H. (2010). Improving measurements of selfregulated learning. Educational Psychologist, 45(4), 267-276. doi: 10.1080/00461520.2010.517150

Wolters, C. A. (1998). Self-regulated learning and college student's' regulation of motivation. Learning and Individual Differences, 90, 224-235.

Wolters, C. A. (2003). Understanding procrastination from a self-regulated learning perspective. Journal of Educational Psychology, 95(1), 179-187. doi: 10.1037/00220663.95.1.179

Wolters, C. A. (2011). Regulation of motivation: Contextual and social aspects. Teachers College Record, 113, 265-283.

Wolters, C. A., \& Benzon, M. B. (2013). Assessing and predicting college students' use of strategies for the self- regulation of motivation. Journal of Experimental Education, 81(2), 199-221. doi: 10.1080/00220973.2012.699901

Wolters, C. A., \& Rosenthal, H. (2000). The relation between students' motivational beliefs and their use of motivational regulation strategies. International Journal of Educational Research, 33(7-8), 801-820. doi: 10.1016/ S0883-0355(00)00051-3

Zimmerman, B. J. (2000). Attaining self-regulation: A social cognitive perspective. In M. Boekerts, P. R. Pintrich, \& M. Zeidner (Eds.), Handbook of self-regulation: Theory, research, and applications (pp. 13-39). San Diego, CA: Academic Press. doi: 10.1016/B978-0121098902/50031-7

Zimmerman, B. (2002). Achieving self-regulation: A Trial and triumph of adolescence. In F. Pajars, \& T. Urdan (Eds.), Academic motivation of adolescents (pp. 1-27). Greenwich, Conn.: Information Age Publ.

Zimmerman, B. (2008). Investigating self-regulation and motivation: Historical background, metodological developments, and future prospects. American Educational Research Journal, 45(1), 166-183. doi: 10.3102/0002831207312909

Zimmerman, B. J. (2013). From cognitive modeling to self-regulation: A social cognitive career path. Educational Psychologist, 48(3), 135-147. doi: 10.1080/00461520.2013.794676

Zimmerman, B. J., \& Martinez Pons, M. (1986). Development of a structured interview for assessing student use of self-regulated learning strategies. American Educational Research Journal, 23(4), 614-628. doi: 10.3102/00028312023004614 